\title{
Un diplomático canario pionero de la lexicografía provincial: Sebastián de Lugo-Viña y Massieu (1774-1852)
}

\author{
JORGE DEMERSON y \\ ÁNGEL MONTERO SÁNCHEZ
}

Personaje bastante descolorido, que no se dio a conocer ni por sus hazañas militares, como varios de sus ascendientes y parientes, ni por sus éxitos de cortesano, de negociante o diplomático, ni siquiera por un brillante enlace matrimonial, pues no se casó ni tuvo descendencia. Sin embargo le conocemos por dos motivos: el primero, indirecto, porque al estudiar la vida de sus tíos, Don Estanislao y Don José de Lugo-Viña y Molina, tropezamos a menudo con su nombre, ya que fue el apoderado en Madrid de estos dos personajes refugiados en Francia desde 1813 y 1818 respectivamente; y el segundo, directo, ya que dejó manuscrita una colección de voces y giros privativos del lenguaje de Canarias, compilación que aprovechó la Real Academia Española para la elaboración de su Diccionario en las ediciones posteriores a 1920 .

Canario como toda su familia, Sebastián de Lugo no nació, al igual que su padre y los tíos suyos que hemos mencionado ya, en la isla de Tenerife. Vio la luz del día en la isla de la Palma, como consta en su partida de bautismo:

En la iglesia del Salvador de esta Ciudad de Santa Cruz de la Palma, en veinte y tres días del mes de Henero de mil setecientos septenta y quatro, yo, el Dr. Don Domingo Alfaro, Prevendado de la Sta. Iglesia Cathedral de estas islas, de licencia del Dr. Don Christóbal Martínez, venera- 
ble beneficiado de dicha Iglesia y familiar del Santo Oficio, baptisé, puse óleo y crisma a un niño que nació en veinte de dicho mes, hijo lexítimo de el theniente-capitán Don Francisco de Lugo y de Doña María de las Nieves Macieu; abuelos paternos, el capitán Don Francisco de Lugo y Viña y Doña María de Molina, vecinos y naturales de la villa de la Orotava; abuelos maternos, el coronel y Gobernador de las Armas Don Phelipe Macieu y Doña María Fierro, vecinos y naturales desta ciudad; al que puse de nombre el de Sebastián Phelipe. Fue su padrino el capitán Don Joseph Fierro a quien hice el exhorto y lo firmé. Cristóbal Martínez. Don Domingo Alfaro de Franchy ${ }^{1}$.

$\mathrm{Su}$ familia, que descendía de los primeros conquistadores de $\mathrm{Te}$ nerife, era de la más rancia nobleza, tenía parentesco con las casas más destacadas del archipiélago y gozaba de una situación económica envidiable.

El padre de Sebastián, Don Francisco Estanislao Timoteo de Lugo-Viña y Molina, sexto heredero de los mayorazgos de su casa, era el mayor de los hijos e hijas que tuvieron sus padres, citados en la partida de bautismo. Nació en la Orotava el 24 de Enero de 1752 y fue bautizado en la parroquia de la Concepción el día 8 de Febrero. Le siguieron Estanislao, nacido el 20 de Junio de 1753, y José, que nació el 11 de Agosto de 1754, también en la Orotava, quienes uno y otro dejarían su nombre en la historia de España o de Canarias ${ }^{2}$.

D. Francisco casó a los 18 años, el 12 de Octubre de 1770, en Santa Cruz de la Palma con María de las Nieves Massieu y Fierro, hija de una ilustre familia de aquella isla. Tuvo tres hijos el matrimonio: María de Jesús Rosa de Lugo-Viña y Massieu, nacida el 4 de Enero de 1772; Francisco Felipe Estanislao, nacido el 5 de Enero de 1773 y Sebastián Felipe de Lugo-Viña y Massieu, que nació el 20 de Enero de 1774, en la Palma como sus dos hermanos. La madre murió de sobreparto siete días después. Huérfano desde la cuna, Sebastián entraba con mal pie en la vida y su mala estrella había de acompañarle fielmente hasta la sepultura.

De los primeros años de Sebastián no sabemos nada. Debió de cursar sus estudios elementales y secundarios en Tenerife, probablemente en la Orotava; en efecto, al quedarse viudo, su padre volvió a

1. Iglesia parroquial del Salvador de Santa Cruz de la Palma, Libro de Bautismos n. 4 , folios 36 vuelto y 37 .

2. Parroquia Matriz de la Concepción de la Orotava, Tenerife, Libro de Bautismos XIV, folios 134,154 y 171 vuelto respectivamente. 
la Orotava en donde era capitán del Regimiento provincial por Real Título de 31-XII-1775. En cambio, para la juventud y madurez de Sebastián no carecemos de información: nos proporciona documentación fidedigna el expediente personal que de él se conserva en el Archivo del Ministerio de Asuntos Exteriores de Madrid, pues este Lugo no se inclinó por la Milicia como su padre y no pocos de sus ascendientes; tampoco optó por la Iglesia como algún tío suyo, sino por la carrera diplomática ${ }^{3}$.

Alrededor de 1793, año en que su tío Estanislao fue nombrado Director de los Reales Estudios de la Corte, Sebastián hubo de trasladarse a Madrid para ampliar estudios en este centro docente. En efecto, en una solicitud de 1807 da ciertos detalles sobre su formación intelectual: «Deseoso de emplearse en el servicio del Rey a imitación de sus mayores, quienes lo han practicado así, ya por la carrera militar, ya en varios otros empleos honoríficos, se ha dedicado en los Estudios Reales de esta Corte con el mayor esmero al estudio de las Humanidades, de la Lógica, de la Filosofía Moral, de las Matemáticas y de la Física Experimental y además se ha aplicado al estudio de las Lenguas vivas, especialmente de la francesa y de la inglesa, que entiende y habla con propiedad, habiendo procurado también adquirir los conocimientos suficientes en Derecho de Gentes y la Economía Política, con el objeto de proporcionarse para el desempeño de algún destino en la carrera diplomática, a la que le lleva su inclinación" ${ }^{4}$.

¿Cuánto tiempo empleó Sebastián en esos estudios? Sin duda bastantes años, pues no fue estudiante precoz y tardó mucho en lanzarse a la vida activa: cuando en 1807 solicita una plaza, tiene 33 años cumplidos; cuando la obtiene en 1810 , tiene 36 . Uno de sus jefes dirá más tarde que el canario era de comprensión muy lenta, circunstancia que explica al parecer la morosidad y parsimonia con que llevó a cabo sus estudios. Suponiendo que los diese por terminados hacia 1800 , ¿a qué actividad pudo dedicarse durante lustro y medio?

A principios de 1807 presenta.un memorial en que solicita la se-

3. Archivo del Ministerio de Asuntos Exteriores, Expediente personal de Sebastián de Lugo, año 1807, leg. 144, expediente 7.223.

4. Ibid., idem, solicitud del 22 de Enero de 1807. En adelante, cada vez que damos como única referencia de un documento su fecha es que se halla en el expediente personal de Sebastián, a la fecha señalada. 
cretaría de la Legación de España en los Estados Unidos (22 de Enero de 1807). No fue atendida esa súplica, pero durante estos años conoció Sebastián a D. Juan Escoiquiz, preceptor que había sido del Príncipe Don Fernando, con quien entabló amistad. Esa amistad, que por lo visto fue estrecha, le valió "padecer persecución con motivo de la causa del Escorial durante el tiránico influjo del privado Don Manuel Godoy» (26-VI-1810). Años más tarde, Sebastián revelará más detalles sobre esta etapa de su vida, afirmando que "unido íntimamente con el Sr. Escoiqui.z, fue su confidente en los sucesos que prepararon la ruidosa causa del Escorial, como se puede ver por las diligencias que se executaron ante el Alcalde de la Corte D. Luis Pereira, con quien casualmente tenía yo amistad, lo que fue causa de que éste me diese el tiempo necesario para evitar una prisión y aquellas injustas persecuciones y me expatriase huyendo a Francia” (20-II-1824). "Tomé el partido de ausentarme de España y de permanecer en París, hasta el principio de nuestra gloriosa revolución" (Mayo de 1808). Así, desde Octubre de 1807 hasta fines de Mayo de 1808, Lugo pasó cuando menos 7 meses en la capital y en el sur de Francia, ya que coincidió en Bayona con Fernando VII, quien le había hecho llamar ${ }^{5}$. Allí «tuvo el honor de presentársele y supo que su Real voluntad era conferirle una plaza en la Secretaría de Estado. Y que así lo decía me consta del Sr. D. Juan Escoiquiz» (7-II-1811). Otra versión, ligeramente diferente, es la que encontramos en otra solicitud de Lugo: «S.M. manifestó al interesado en Bayona, cuando tuvo el honor de presentársele allí, que le darían una Secretaría en la Legación. Solicitó la Secretaría de Londres y el Señor Ministro de Estado le dijo que le proporcionaría la Secretaría de Legación de los Estados Unidos en América cuando resultase vacante. Razón por la que solicita ahora esta plaza pues está vacante» (26-VI-1810).

De regreso en la península, en Junio de 1808, Sebastián de Lugo permaneció algún tiempo en la Corte, alojado tal vez en casa de su tío Estanislao, quien desde el principio se había adherido al partido del Intruso y fue por esto nombrado Consejero de Estado. De buen o mal grado, Sebastián hubo de convivir en la capital española con las tropas de ocupación y con los josefinos que habían optado por el rey José I. Pero al finalizar el año 1808, pensando que en Sevilla, donde los partidarios de Fernando VII habían formado un gobierno que se oponía al de José Bonaparte, tendría tal vez la oportunidad de obte-

5. Despacho del embajador Carnerero, Viena, 30-X-1822. 
ner esa Secretaría de Legación con que soñaba y que le había prometido el Rey en Bayona, Sebastián emprendió el viaje de Madrid a Sevilla. No le salió el proyecto tan bien como lo esperaba. Denunciado como sospechoso de colusión con el invasor, fue detenido en Andalucía, se le formó expediente y, sin que fuera sometido a pleito, el Tribunal de Seguridad Pública de Sevilla decretó su confinación a Medina Sidonia por auto de 28 de Febrero de $1809^{6}$.

Inmediatamente protesta el interesado por medio de una representación a la Junta Suprema en la que se queja de la providencia de este tribunal que le confina a Medina Sidonia. Al recibir esa queja, la Junta Suprema pide a D. Ramón Pingarrón, presidente del citado Tribunal, "que informe lo que se le ofrezca y parezca» (3-III-1809)?.

El magistrado contesta a Don Martín de Garay que los motivos del confinamiento a que fue condenado Sebastián de Lugo son «el ser sospechoso, poco adicto a nuestro actual gobierno y despreciador de sus providencias, a que se agrega ser un sobrino de Don Estanislao de Lugo, Consejero de Estado del Rey intruso".

Lugo había representado a la Junta Suprema sobre los perjuicios que sufría por su confinación y pidiendo que se le formasen cargos y administrase justicia, como se debe a todo vasallo. Volviendo a reconocer la causa, el Tribunal declara que «se ha convencido de la ligereza con que Lugo se resolvió a molestar la atención de V.M.» y ratifica su decisión anterior. "En la conducta observada por Lugo desde el momento que pensó salir de Madrid, escribe el Sr. Pingarrón, hasta su arribo a esta ciudad [Sevilla], se advierte algo más que flaquezas, Se preservó de los temores o insultos de un reconocimiento de los enemigos por un pasaporte firmado por el general Beliart, que le facilitaría o su actividad colaboracionista o la posición de su tío Estanislao, quien, según confesión de su sobrino, en la primera irrupción de los enemigos, ha sido agraciado con una plaza de Consejero de Estado y en la segunda ha prestado el juramento de fidelidad y obediencia al intruso. En Toledo repitió esta diligencia, protegiéndose con otro pasaporte del comandante de las armas enemigas... Su indiscreción, cuando no imprudencia, llegó al extremo de suscitar con frecuencia

6. Archivo Histórico Nacional, Madrid, Estado, leg. 29 G, documentos 213 a $213^{11}$. Contiene todo lo referente al viaje a Sevilla y confinación en Medina Sidonia.

7. A.H.N., Estado, leg. 29 G, n. ${ }^{\circ} 213$ (3-III-1809). 
por materia de conversaciones el sistema de nuestro gobierno, increpándole con los dictados de absurdo, indolente, monstruoso y nada sigiloso". La sorpresa que al oirle recibian sus compañeros de viaje no bastó a contenerle. Todos estos hechos, decía el Sr. Pingarrón, daban pie a los jueces para condenar a Lugo al confinamiento en Medina Sidonia.

Esta sentencia, confirmada por otras dos, le había sido notificada en persona. $Y$, no habiendo sobrevenido motivo alguno de modificar su juicio, el Tribunal piensa que debe desestimarse la solicitud de Lugo, «pues no tenía otra finalidad que la de obtener, gracias a la audiencia que solicita, los nombres de los sujetos que puedan haber "acriminado su conducta" y fueron sus compañeros de viaje, y na es justo comprometer la rectitud y fidelidad de éstos ${ }^{8}$. Además, añade Pingarrón, Lugo no es acreedor a la indulgencia del Tribunal por la impostura que cometió al escribir que los jueces no habían resuelto aún sus instancias.

A pesar de su postura intransigente, el Sr. Pingarrón se llevó un chasco: "La Suprema Junta de Gobierno del Reyno, en vista del informe del Tribunal a 21 de Junio último sobre la representación de D. Sebastián de Lugo, se ha servido acordar que se le oiga en justicia como solicita” ${ }^{9}$. Finalmente la vista con tanto ahínco reclamada por el canario se verificó, y en ella Lugo consiguió lavarse de todas las acusaciones y sospechas que existían contra él, quedando totalmente absuelto, pues el Tribunal de Policía dictó providencia a su favor en la isla de León el 12 de Marzo de 1810 en que se le declara por buen patriota, y acreedor a la protección del Gobierno ${ }^{10}$. A raíz de esto, Lugo firma una solicitud en la que de nuevo pretende la Secretaría de la Legación de España en Estados Unidos (26-VI-1810).

Prosperó el proyecto, pues por decisión fechada en Cádiz a 5 de Agosto de 1810 y transmitida al Ministro español en Filadelfia, don Luis de Onís, se decía que «ha dispuesto S.M. que D. Sebastián de Lugo pase a Filadelfia sin más título ni objeto que el de permanecer en un todo a las órdenes de V.S. y de trabajar en cuanto se le mande, sin derecho a reclamar la mesa y casa de V.S., y V.S. le socorrerá con

8. Ibid., Idem. (21-VI-1809). Argumento especioso, pues Lugo afirma que uno de sus compañeros de viaje era primo suyo.

9. Ibid., idem, (2-VII-1809).

10. 12 -III-1810. 
mil reales de vellón mensualmente que cargará en sus cuentas de gastos extraordinarios". Asimismo, le conceden 12.000 rs. de Vn por una vez para que pueda emprender su viaje con este auxilio. (10-VIII-1810). A esas alturas, ya estaba enterado el interesado de la Real resolución, pues observa en un escrito que "para conciliar la decencia con la economía convendría pudiera tener uso de un uniforme y suplica se le conceda el uso del uniforme de capitán de Milicias". Y en efecto, S.M. le permite que pueda usar, fuera de España, el distintivo de capitán de Milicias.

El 6 de Octubre de 1810, don Luis de Onís anuncia la llegada a Filadelfia de su nuevo colaborador en un barco procedente de Lisboa. No tarda el canario en manifestar su carácter descontentadizo. Amargado por no tener un empleo bien definido y estar "en un todo pendiente de las órdenes del Ministro", redacta un largo memorial en que pide se le nombre Secretario de la Legación española en Filadelfia (7-II-1811, o sea 4 meses justos después de su llegada). En ese escrito recuerda que antes de 1807 se comprometió en favor de Fernando VII, que la causa del Escorial le obligó a huir a Francia y que luego el viaje que hizo de Madrid a Sevilla le mereció once meses de confinamiento en Medina Sidonia.

Desde Cádiz, la Junta Central, que parece muy bien dispuesta hacia Sebastián, contesta que «concede a Lugo la correspondiente gratificación alimenticia de que disfrutan los demás agregados a la Legación de Filadelfia que no viven en casa del Ministro" y dice a don Luis de Onís «si V.S. halla que D. Sebastián es un sujeto de conocida probidad e inteligencia, puede V.S. habilitarle de Secretario a ese Ministerio de S.M. pues cuando el Consejo de Regencia le envió a ese país fue porque tuvo muy presentes los méritos que contrajo con el Rey D. Fernando VII, lo que padeció por su causa y el aprecio que S.M. hacía de su persona» (30-IV-1811).

Tenemos buenos motivos para creer que D. Luis de Onís «no halló que D. Sebastián reunía las condiciones que hubieran permitido habilitarle como Secretario del Ministerio de Asuntos Exteriores, pues no sólo no propuso su nombramiento para dicho empleo, sino que dos meses después, "pedía que trasladasen a otro sitio al D. Sebastián" (12-VIII-1811). Sólo había tardado cuatro meses (o seis) Sebastián de Lugo en hacerse indeseable en la Legación española de Filadelfia.

La petición de traslado formulada por el Sr. de Onís no surtió 
efecto inmediato. Durante más de cuatro años hubo de aguantar el ministro a ese colaborador del cual traza un retrato nada favorable: "...He observado en Lugo un carácter turbulento y díscolo, propenso a la insubordinación y a la calumnia, reuniendo las malas propiedades de inaplicación y desidia y más que todo la falta de reserva y sigilo aun en las materias más sagradas de aquella Secretaría... Que no han servido las amonestaciones sino para oir de su boca insultos y provocaciones ominosas, propias del lenguaje de los demócratas más atrabiliarios y soeces del pueblo y de los extranjeros de peor nota con quienes tenía conexiones íntimas, al paso que no trataba con los buenos españoles contra quienes levantaba atroces calumnias sin perdonar al mismo enviado su jefe, jactándose de que la protección que decantaba tener en la Corte destruiría sus contrarios y él obtendría los destinos primeros de la Monarquía». (14-VII-1815).

Esas críticas durísimas pero generales estribaban al parecer en hechos concretos. Por lo visto, Lugo denunció a Madrid una licencia para conducción de armas concedida por D. Francisco Caballero Sarmiento, que había sido comisionado de la Caja de Consolidación con Estados Unidos. En esa denuncia involucraba a varios compañeros suyos de la Legación e incluso a su jefe, el Ministro de España en aquella ciudad. "Origina esa denuncia el correspondiente expediente que con alegatos, contraalegatos, informes y testimonios resulta muy abultado". Es evidente que las relaciones de Lugo con sus superiores y compañeros hubieron de enfriarse de tal modo que resultaba imposible la convivencia entre ellos. La única solución era el traslado del perturbador $^{11}$.

Las quejas graves y pormenorizadas del Sr. Onís que acabamos de citar aparecen en un informe que el ministro enviaba a Madrid al finalizar la misión de su colaborador en Filadelfia. Pero el Ministerio estaba informado ya tiempo atrás. La decisión de destinar a Lugo a Hamburgo es del 3 de Agosto de 1814 y el interesado no podía ignorar que estaba pendiente de un traslado. Pero sólo le llegó su nombramiento para Hamburgo a fines de Junio de 1815 (Carta autógrafa de Lugo, 30-IX-1815, desde Hamburgo). Expone que llegó a Alemania pocos días, pasando no por España, sino por Inglaterra. $\mathrm{Y}$ en este mismo escrito, brusca y brutalmente, sin dar tiempo al tiempo, pide inmediatamente que le aumenten el sueldo de 12.000 rs que se le

11. Véase José Pérez Vidal, Introducción a la Colección de voces y frases provinciales de Canarias por D. Sebastián de Lugo, 
asignaba, pues «Hamburgo es una de las ciudades más caras de Europa». Esa petición no surtirá efecto y un poco más tarde el Ministerio puntualizará que D. Sebastián es nombrado Secretario de S.M. cerca de las Ciudades Anseáticas con el sueldo de $12.000 \mathrm{rs}$ al año, y la casa y mesa que deberá darle el ministro (30-XI-1985). Asimismo, le conceden por vía de ayuda de costa para hacer frente a los gastos del viaje otra cantidad de 12.000 rs.

Las relaciones algo tensas que mantenía nuestro Secretario de Legación con el Ministerio madrileño de que dependía no podían redundar en beneficio del canario; no iban a mejorar el concepto que de él tenían ni tampoco conseguirle el aumento de sueldo que con tan escasa diplomacia reclamaba a gritos. Con todo, él se aferra a esa actitud de reivindicación, multiplicando los escritos apremiantes, de tono casi agresivo. En Enero de 1816, se queja de que lleva siete meses sin cobrar; y añade que vino de Estados Unidos por Inglaterra sin pisar el suelo patrio y que resultó insuficiente la ayuda de costa que se le concedió para hacer el viaje (12-I-1816). Más tarde deja asomar el carácter entre conspirador y soplón que manifestara ya en su colaboración con Escoiquiz: escribe a Madrid solicitando licencia para pasar a la Corte desde Hamburgo, de cuya residencia era Secretario, para enterar personalmente al Rey de los manejos de Onís y otros sujetos en los Estados Unidos, y repite luego esa solicitud «para comunicar un asunto de importancia". Le contestan que no venga, que exponga por escrito las informaciones o noticias que posee de modo que puedan enterarse Onís y Sarmiento y defenderse de esas acusaciones (27 y 28 de Mayo de 1816).

Abandonando la denuncia de escándalos, pues ve que las autoridades, con inclusión del Rey, le hacen poco caso, Lugo vuelve a sus reclamaciones crematísticas. En una larga súplica autógrafa, pide que se le paguen los sueldos atrasados de Secretario de la Legación de Hamburgo, y además, las mesadas de Julio, Agosto y Septiembre de 1815, que se le deben como agregado de la Legación de E.U. (29-VIII-1818). Sobre este último punto, la contestación es una negativa rotunda.

La estancia en Hamburgo debió de serle beneficiosa de algún modo a Lugo; aprendió y sin duda llegó a dominar el alemán, ya que, cuando se trató de darle otro destino, se le nombró para otro país germánico: Austria. Por oficio del 11-IV-1820, Lugo se enteró de que «el Rey se ha servido nombrar a $V$. oficial de esa embajada en Viena con 
el mismo sueldo de 12.000 rs. que ahora disfruta». Más tarde, se puntualizará el grado del empleado: "segundo Secretario de Legación con 12.000 rs de sueldo". Se ve que, a pesar de sus años de servicio, Sebastián de Lugo no asciende y sigue cobrando el mismo sueldo que tenía años atrás (18-XII-1820). Reacciona inmediatamente (13-1-1821) pidiendo que uel destino de Segundo Secretario de Legación no le perjudique en ulteriores ascensos por ser el más antiguo de los empleados". Susceptible, secreto, arisco, el hombre resultaba desconcertante..

$\mathrm{Su}$ jefe en Viena, D. Mariano de Carnerero, que le conocía desde hacía veinte años, escribe al Ministro D. Evaristo San Miguel tratando de definir la personalidad y el carácter de su colaborador: «D. Sebastián de Lugo es el secretario de esta Legación. Hace bastantes años que le conocí cuando ambos estudiábamos en San Isidro en esa Corte, aunque en diferentes clases, y me consta que ha recibido una esmerada educación... Luego se refiere que unido íntimamente con el señor Escoiquiz, fue su confidente en los sucesos que prepararon la ruidosa causa del Escorial, por cuyo compromiso tomó el partido de ausentarse de España y de permanecer en París hasta el principio de nuestra gloriosa revolución. Su patriotismo en aquella época creo que es indudable, pero habiendo hablado con cierta libertad de la Junta Central y de algunos de sus individuos fue delatado y desterrado a Medina Sidonia donde residió unos once meses hasta el establecimiento de la primera Regencia. Aclarada su inocencia y en retribución de sus sufrimientos, fue nombrado agregado a la Legación de Estados Unidos. Allí se indispuso con el Ministro D. Luis de Onís y en 1814 fue nombrado Secretario de la Legación del Rey en Hamburgo, donde desempeñó las funciones de encargado de negocios un poco de tiempo. De Hamburgo vino a esta embajada como oficial de ella y después ha quedado con el título de Segundo Secretario.

No puede decirse que no tenga conocimientos; pero hallo mucho desorden en sus ideas, uná lentitud extraordinaria en su comprehensión y una confusión en fin en sus raciocinios, que le hacen incurrir en contradicciones y en errores... Su conducta política es plausible; respira patriotismo y el amor más acendrado por la prosperidad y glorias de la Nación. Su adhesión al sistema constitucional y su celo por su conservación me parecen incontestables; pero, violento en sus opiniones, exagerado en sostenerlas, intolerante en cuanto ve la menor contradicción a sus argumentos, es casi imposible entrar con él pacíficamente en discusión sobre esta materia, tanto más cuanto do- 
tado de un carácter vengativo y rencoroso, al momento desciende de las teorias a las personalidades y no hay honra que no ataque ni plan descabellado que no apruebe como lo crea útil para satisfacer su odio contra los que presume que son sus enemigos. Le he oído hablar bien solamente de tres o cuatro personas y como este carácter, que será muy patriota y muy excelente, es sin embargo, enteramente contrario al mío, he interrumpido con él todo trato familiar y no le veo sino en los momentos que requieren las atenciones del servicio" (30-X-1822).

Sin duda el despacho del embajador Carnerero en que trazaba un retrato psicológico poco halagüeño de Lugo provocó el cese del Sẹgundo Secretario de la embajada de Viena y su convocación en Madrid: "En el año 23, me restituí a España de Real Orden» confiesa Sebastián. Nos consta en efecto que a fines de Agosto de 1823 el canario estaba en Cádiz; dos veces desde aquella capital pide certificación de sus años de servicio para obtener su clasificación y el arreglo de su sueldo.

También en Cádiz, desde el mes de Junio, estaba Fernando VII, tras dejar èl gobierno de la Nación en manos de la Regencia (11-VI-1823). ¿Pudo Lugo entrevistarse con el Rey? Si lo consiguió, fue una gestión inútil, pues a partir de 1823 el ex-cómplice de Escoiquiz queda constantemente en situación de cesante, sin obtener nunca un nuevo empleo. En Cádiz debía de seguir todavía cuando el Duque de Angulema y los "Hijos de San Luis" rindieron el fuerte del Trocadero (31 de Agosto) y el castillo Santi Petri (20 de Septiembre); fáciles victorias que hicieron por segunda vez pasar a España de la monarquía constitucional a la monarquía absoluta, como la que se restableció en 1814.

Desprovisto de todo, sin ayuda, sin empleo, Lugo se embarca para su patria chica: «reducido a la clase de cesante y sin cobrar sueldos, pasé a las islas Canarias, mi patria, habiendo pedido permiso a S.M., a fin de proporcionarme allí medios de subsistencia de que carecía absolutamente en la península». Desde «la villa de la Orotava de Tenerife", convirtiéndose de nuevo en pretendiente, recuerda en una súplica las pruebas de patriotismo que había dado en la guerra de la Independencia y los méritos que contrajo en servicio de nuestro soberano en la Causa del Escorial... servicios que le acarrearon injustas persecuciones y le obligaron a expatriarse a Francia. En vista de dichos méritos, solicita «una plaza en la Secretaría de Estado, o el ascenso» (20-II-1824). 
También se hace esperar la contestación a esa carta. Lugo aprovecha pues su estancia en el archipiélago para visitar a su numerosa parentela, repartida por toda la isla de Tenerife, ocuparse de los bienes que le tocaron en esa isla, concretamente en la Orotava, cuna de su familia; asimismo es probable que continuara las investigaciones que habia emprendido en sus años mozos sobre las particularidades provincianas del castellano hablado en las distintas islas de Canarias.

Finalmente, la contestación que esperaba del Ministerio y que se había extraviado, llegó a sus manos. En ella se le informaba de que antes de poder cobrar su sueldo tenía que someterse a purificación. En efecto, el día $1 .^{\circ}$ de Abril de 1824 había salido un decreto restableciendo las purificaciones que ya se habían practicado a partir de 1814 , a raíz de la Guerra de la Independencia. Avisan pues a Lugo para que vaya a la Corte a ponerse en regla:

«El conde de Ofalia que desempeñaba en aquel tiempo el Ministerio de Estado, me escribió con fecha de 28 de Abril del año último (1824) a dichas islas que S.M. se había servido restablecer la Junta de purificaciones, cuyo oficio recibí con atraso y me restituí a la Corte inmediatamente me fue posible para ponerme a disposición del gobierno. Presenté mi cédula para purificación el 28 de Noviembre de dicho año (1824). Pero, a mi vuelta de Canarias, los insurgentes de Colombia (?) hicieron en mí un horrible despojo" (26-XI-1825).

Paralelamente, desde San-Lorenzo, el Ministerio escribía al Superintendente General de Policía para informarle de la llegada a esta Corte, procedente de Canarias, de D. Sebastián de Lugo, empleado en la carrera diplomática y «debiendo purificarse este empleado antes de ser repuesto en su destino, se servirá V.S. informar lo que sepa o pueda adquirir acerca de su conducta política durante el régimen constitucional» (25-XI-1824). Con la misma fecha y con idéntico tenor se dirige otro oficio al Ministro de S.M. en Viena pidiendo información acerca de la conducta política de Lugo durante su permanencia en esa capital.

Es más que probable que esa encuesta no resultó muy favorable al hijo de La Palma, ya que, como lo escribía el Sr. de Carnerero "su adhesión al sistema constitucional y su celo por su conservación parecían incontestables».

Esos trámites administrativos resultan interminables, porque las respuestas tardan en llegar; sólo en Mayo de 1825 envía el emba- 
jador en Viena, Carlos Cruzmayor, el informe del barón de Stürmer, Canciller de Estado, en ausencia de S.A. el Príncipe de Metternich. Gracias a estas informaciones, Lugo queda purificado "en primera instancia» en 1827. Pero ello no basta. Se piden al interesado nuevas precisiones, nuevos datos que no puede facilitar: "Cuando me restituí de Viena a España, al año veinte y tres, explica, una partida en Castilla robó la mayor parte de mi equipaje que lo conducian unos arrieros, perdiendo yo en aquella ocasión muchos de mis papeles» (17-V-1828). Harto de esperar y sin recursos, Lugo en Septiembre de 1828 , suplica que "se le clasifique el sueldo" pues ya hace un año que se purificó en primera instancia. Pero no consiguió nada. Una y otra vez vuelve a la carga: el 2 de Julio y el 25 de Septiembre de 1829, el 22 de Abril de 1830 extiende otras memorias reclamando que "se le iguale el sueldo". Finalmente, siete años después de concluido el trienio constitucional, la Junta de clasificación declara que el 6 de Octubre de 1828 -es decir ¡dos años antes!- se reconoció a Lugo 12 años, 2 meses y cinco días de servicio, correspondiéndole 4.000 rs anuales, tercera parte del sueldo de 12.000 rs que cobraba en su último destino en Hamburgo como Secretario de Legación. ¿Por qué ni siquiera se alude a los servicios que prestó en la embajada de Viena de 1820 a 1823, aunque esos servicios se contabilizaron? Misterio... o injusticia.

Una doble evidencia se nos impone a estas alturas. En 12 años de servicio, no consiguió ascender el desdichado Sebastián: seguía cobrando 12.000 rs en su último destino al igual que en el primero; y cuando se le integra en el escalafón diplomático, se le nombra segundo secretario de Legación, aunque, como lo nota el propio interesado, es el más antiguo de los empleados de la embajada. Sin duda deberá esa postergación a su mal carácter, a sus prontos, a su desidia y a su postura política favorable a la Constitución. Se ve con meridiana claridad que el Rey, a quien había ayudado con abnegación en 1807, no le quiso ayudar ni en 1820, ni en 1823, ni después, cuando de purificación o de clasificación se trató.

No rios consta que después de esa «clasificación» Lugo haya obtenido otro empleo al servicio de la monarquía. A partir de 1830 y en varias ocasiones, su presencia en la península queda documentada. Pero, aunque al darle en 1831 un poder para cobrar su pensión, Don José le dice «agregado a la Primera Secretaría de Estado" en Madrid, no hemos encontrado el nombramiento correspondiente y, en otro 
documento, el propio Sebastián se identifica como «ex-secretario de embajada".

De resultas de ello, Sebastián anduvo siempre muy corto de dinero. A partir de 1823, o tal vez de 1826, cuando le cesan, sólo pudo contar con $4.000 \mathrm{rs}$ al año hasta que se purificase; y luego su pensión quedó limitada a 4.000 rs. Encima, el Erario, exhausto por los gastos y desperfectos de la guerra, se mostró constantemente remiso para pagar. De forma que Sebastián, que fuera de algún censo de Canarias, no tenía más ingresos que su sueldo, conoció frecuentemente apuros de dinero, circunstancia que explica tal vez la intransigencia que manifestará en las diferencias de intereses que le opusieron más tarde a algunos familiares suyos.

En efecto, en 1833 se produjo un acontecimiento que afectó directa e indirectamente a la familia Lugo. El 25 de Agosto de aquel año fallecía en su piso de la rue Porte-Dijeaux, $n .^{\circ}$ 67, de Burdeos, D. Estanislao de Lugo, tío de Sebastián, que el 20 de Junio anterior había cumplido los 80 años. Se ignora la causa de su muerte, pero es posìble que ésta se haya de relacionar con la terrible epidemia de cólera que durante ese año y el siguiente asoló buena parte de la Europa occidental. Entre los papeles del finado apareció un testamento ológrafo fechado en 3 de Enero de 1826. Aunque existieron varias copias de este documento -Don José de Lugo poseía una copia en español y una copia de la traducción francesa del mismo, como lo revela el inventario de sus bienes, y Sebastián una copia en español- no conocemos hasta la fecha el texto escrito por Don Estanislao ${ }^{12}$.

Por lo que pudimos colegir, gracias a lo que se dice en el inventario de los bienes de Don José de Lugo, Estanislao instituía a su hermano José por "heredero general" de todos sus bienes, menos una manda que destinaba a su hermana Estéfana (nacida el $1 .^{\circ}$ de Septiembre de 1771 en La Orotava), y caso de fallecer ésta, a su sobrino Sebastián. Ahora bien, habiendo fallecido ya Estéfana (el 15-XII-1834), Sebastián consideraba que esa manda había de revertir en él.

Concretamente, el objeto del litigio constaba de dos partes:

12. Archivo departamental de los Altos Pirineos, Tarbes, Notaría de Etienne Daube, año 1837, mes de Marzo. Inventario de los muebles, efectos y papeles del difunto D. José de Lugo (del n." 115 al 140), fol. 52. 
1) una renta sobre los fondos públicos franceses al $5 \%$ de pital de 19.000 francos a nombre de dicho Estanislao de Lugo [«adquirida antes de su muerte» puntualiza algo ingenuamente el inventario].

2) un crédito sobre la Casa de comercio Cabarrús y Compañía de Burdeos, de 68.045 f. 90 céntimos. En total un capital de 87.045 f. 90 cts. Pero "los requirentes del inventario" o sea los herederos de don José, creen que esa renta ha sido aumentada de los dividendos pagados por la casa Cabarrús, pero ignoran el importe de los dividendos abonados y piensan que el crédito quedará reducido al $30 \%$.

La diferencia entre Don José y Sebastián concernía únicamente estos puntos 1 y $2:$ «El difunto Don José de Lugo se pretendía propietario de la renta (N. ${ }^{\circ}$ ); pero Don Sebastián, su sobrino, sostiene que no pertenece a Don José, heredero general, sino a los legatarios particulares, lo mismo que el crédito señalado en el n. ${ }^{\circ}$ 2». Otro punto de litigio existía: Don José quería que la sucesión de Estanislao se liquidase en Francia; y Sebastián pretendía que lo fuese en España ${ }^{13}$.

Manifestando ese carácter arrebatado que habían denunciado ya los señores de Onís y Carnerero, Sebastián no vaciló en intentar un pleito a su anciano tío ante los tribunales españoles, y eso a las pocas semanas de conocer el testamento de Estanislao. Lo confiesa en una carta a Don Andrés Villalba: «Sebastián de Lugo nada desearía más en el día que tener un ascenso en su carrera, pero por ahora esto no podrá ser, pues le es necesario permanecer en Madrid con motivo de un pleito que tiene con su tío D. José de Lugo, residente en Francia, a quien ha citado ante un tribunal de Madrid, y cuya citación irá por el Ministerio de Estado uno de estos días a Francia ${ }^{14}$.

Pero, a fines de Noviembre la situación es algo diferente. Sin duda porque por motivos de salud, D. José hubo de informar a su sobrino que no podía personarse ante el tribunal madrileño a causa de sus muchos años y de su salud quebrantada: tenía entonces 79 años. Pedía en cambio a Sebastián que fuera a Bañeras para estudiar con él la posibilidad de hallar una solución a sus diferencias. Esto se desprende de una carta que escribe Sebastián a D. Francisco Zea Bermúdez, primer secretario de Estado y del Despacho:

13. Inventario citado, fol. 55 vuelto.

14. Arch. Min. Asunt. Ext., Leg. 144, Expediente personal 7.223. 
Muy Sr. mío: Habiendo fallecido en la ciudad de Burdeos a fines de Agosto último mi tío D. Estanislao de Lugo, mi otro tío D. José, hermano del difunto, residente en el lugar de Bañeras, ya de mucha edad y de una salud quebrantada, me ha instado repetidas veces, y en particular últimamente, que vaya por un poco de tiempo a su compañía para ayudarle en arreglar algunos asuntos de familia, y así ruego a V.E. tenga la bondad de elevar a S.M. la Reina Gobernadora mi súplica de que se digne concederme su real permiso para pasar a Francia por cuatro meses; y al mismo tiempo que S.M. me conceda esta gracia por el justo motivo que he indicado, que no presenta ningún inconveniente al servicio, mediante a hallarme en la clase de cesante, ruego a V.E. igualmente se dé aviso al Real Giro de estar yo ausente con Real permiso, para poder seguir cobrando la corta asignación que disfruto de cuatro mil reales anuales" (26 de Nov. de 1833).

De hecho, Sebastián pasó al país vecino. Hubo de cruzar la frontera en los primeros días o meses de 1834, yendo tal vez en derechura a Burdeos, donde residiera su tío Estanislao durante veinte años (1813-1833). Allí, posiblemente, Sebastián estableciera contacto con el abogado Maître Fleuri Godde, a quien posteriormente dio un amplio poder. Luego se dirigió a Bañeras donde pasó varios meses: su presencia en el balneario queda documentada el 14 y 15 de Abril, el 12 de Junio, el 4 de Julio y el 12 de Agosto. Queda pues probado que Sebastián permaneció cuando menos 4 meses en Bañeras -del 14 de Abril al 12 de Agosto de 1834-; mas es posible que haya llegado mucho antes, acaso desde Enero ya que tiene que pedir una prórroga al permiso que se le dio inicialmente: «Desde el primero de Enero, tengo permiso por cuatro meses para ir a Francia -escribe a D. Francisco Martínez de la Rosa- por haberme instado mi tío José a que pasase un tiempo en Bañeras para arreglar unos asuntos de familia. Pido licencia para otros dos meses más por no haber resuelto todos los asuntos; y que me sigan pagando los 4.000 rs por el Real Giro» (14-IV-1834, Bañeras). Al ignorar las fechas exactas en que Sebastián llegó a Francia, sólo podemos decir que permaneció en ese país de cinco a ocho meses, habiendo obtenido una o dos prórrogas.

Lógicamente, si venía sólo a Francia para hablar con su tío José y procurar solventar con él la espinosa cuestión de intereses, Sebastián se alojaría en el Gran Hotel Frascati, propiedad de su repetido tío, adonde iban a recalar todos los españoles que llegaban a Bagnères. Pero pronto las relaciones se fueron poniendo muy tensas entre los dos hombres. Cuando, ya el 15 de Abril, Sebastián confiere un poder general y especial para "oponerse a que el testamento ológrafo del difunto Don Estanislao se deposite en una notaría de la ciudad de Burdeos, como se propone solicitarlo don José de Lugo, uno de los 
herederos testamentarios", este paso representa una verdadera declaración de guerra, que viene a confirmar otro párrafo del mismo documento. Dice expresamente que se ha de "notificar por vía judicial al citado Don José de Lugo el declinatorio de que se trata, protestando que el constituyente defenderá los derechos que a su favor resultan de dicho testamento ante los tribunales españoles, citando ante ellos, caso necesario, al repetido D. José de Lugo y demás legatarios». Aun admitiendo que Sebastián se hospedara en Frascati, no podemos creer que fuera con frecuencia a visitar a su anciano tío -que tenía entonces 80 años- en su retiro de Salut ${ }^{15}$.

Lo cierto es que las cosas pasaron a mayores. Hubo pleito, lo que no imaginaría sin duda Estanislao al extender su testamento: "Hay pleito en este punto -la pertenencia de la renta y del crédito de que hemos hablado más arriba- ante la Audiencia de Burdeos» (Inventario, fol. 55 v., Marzo de 1837). Como se echa de ver por la última frase del inventario, el asunto no se había zanjado antes de la muerte de D. José. No sabemos cuándo falló el Tribunal bordelés, ni cuál fue la sentencia que dictó.

De todas formas, ésta no podía agradar a Sebastián. Desde un principio se había opuesto a que el asunto se juzgase en Francia, pues decía con no pocos visos de razón: el testador era español, españoles los herederos y españoles también tres de los albaceas. Se trataba de un pleito entre españoles y que era exclusivamente de la incumbencia de los tribunales de España. De regreso a Madrid, Sebastián interpuso recurso de injusticia notoria ante el Tribunal Supremo de Justicia de la Corte "para poder usar de los derechos que pudieran corresponderle y consistían en un legado vitalicio dejado por el testador en cabeza en primer lugar de Doña Estéfana de Lugo, tía del otorgante, en que había de sucederle él después de su muerte, y habiéndose verificado ésta antes del referido pleito, se opusieron los hijos de D. José de Lugo a concederle la posesión en pleno dominio de este legado". Supongo que fue entonces cuando Sebastián, viéndose atrapado en un callejón sin salida, intentó conseguir la anulación pura y simple del testamento de su tío, maniobra a la que se alude èn algunos documentos. Pero fracasó en su intento, pues meditando largamente su sentencia, el Tribunal Supremo de Madrid declaró que el

15. Sobre D. José de Lugo y sus largas estancias en Bagnères véase: Jorge Demerson, "Un canario diplomático y hombre de negocios: Don José de Lugo-Viña y Molina», Instituto de Estudios Canarios, de próxima aparición. 
testamento ológrafo era perfectamente válido. El pleito quedaba pues empantanado, ya que al parecer los argumentos de las dos partes se equilibraban. Si cada una de ellas permanecía en sus trece, el litigio podía resultar parado indefinidamente. De modo que para todos la vida volvió a transcurrir tranquila y hasta monótona.

Singularmente, la de Sebastián ya jubilado, y en la que no pasaba casi nada. A pesar del pleito que le oponía a su tío, el sobrino tuvo un detalle simpático: el 23 de Junio de 1835, escribió al conde de Toreno, entonces embajador de España en París, pidiendo que D. José, en vista de sus muchos años y achaques, pudiese permanecer en Bañeras y cobrar allí los 6.000 rs anuales de su pensión. El conde, algo mezquinamente, le concedió este favor "hasta fin de año» ${ }^{16}$.

En 1844, Sebastián recibió un oficio de la Administración tinerfeña que le pedía cuentas de los bienes que posẹía en el municipio de La Orotava. No sabemos si tuvo que personarse en la isla o si pudo arreglar el asunto desde la Corte. Pero este incidente hubo de hacerle volver cuando menos mentalmente a la tierra de sus mayores. Ayudándose probablemente con apuntes tomados en Tenerife, tal vez en otras islas, durante sus años mozos, datos ampliados posiblemente cuando en 1824 pasó una temporada en el archipiélago, Sebastián recopiló entonces o puso en limpio una Colección de vozes y frases provinciales de Canarias cuyo manuscrito llevaba la fecha de 1846 y que no llegó a publicar su autor. Sólo tres cuartos de siglo después, en 1920 , interesado por estos apuntes que habían llegado a sus manos, el conde de la Viñaza decidió darlos a la imprenta.

En realidad, la historia de esa Colección es algo más compleja que lo que sugiere este resumen esquemático. Las notas o cédulas de D. Sebastián fueron a parar no sabemos cómo en manos de Bartolomé Gallardo, muy aficionado a los papeles raros o curiosos, quien sacó de ellas una copia. Hoy día se ignora el paradero del manuscrito original. Pero la copia de Gallardo pasó en poder del conde de la Viñaza, académico de número de la Real Academia Española, quien la entregó a la Comisión del Boletín de la misma para que la publicase. Efectivamente, la Colección aparece en el Boletín de la Real Academia Española, Año VII, tomo VII, Junio de 1920, como una fiel reproducción de las papeletas de Gallardo: Coleczión de vozes..., pero sin más introducción o comentario que una nota de cinco renglones al pie de

16. A.H.N., Estado, leg. 3.429/15, 23 de Junio de 1835. 
la primera página. Aprovechando esta publicación, la Academia insertó no pocos vocablos de esta colección en la edición de 1939 de su Diccionario.

En 1946, cien años justos después de que Sebastián pusiera la fecha a su manuscrito, el profesor José Pérez Vidal, canario, del claustro de la Universidad de La Laguna, hizo una segunda edición, científica, de esta colección lexicográfica, con una introducción de 35 páginas dividida en tres partes: I) Propósito y justificación (de esta publicación) en que denuncia las muchas erratas y errores que afean la edición de 1920 (págs. 5-7); El Autor, en que hace un esbozo biográfico de Sebastián de Lugo, ligero, pero documentado y exacto (págs. 7-15); III) La colección: su autenticidad y sus errores, estudio serio y crítico de las voces y frases recogidas (págs. 15-40) ${ }^{17}$.

Según Pérez Vidal, la redacción de los artículos se hizo lejos de la isla, sin duda en Madrid, pero la existencia de todas las voces recogidas queda comprobada. Señala erratas debidas unas a Sebastián, otras a Gallardo. Pero reconoce que esta colección tiene el mérito de ser la primera de este género en el archipiélago canario y una de las primeras que en España se dedicaron al habla popular. El editor juzga muy positivo el trabajo de Lugo, ya que ío clasifica como «fruto interesantísimo del reconfortante entretenimiento de un anciano" (p. 15). Es el único estudio literario o científico que conocemos de Sebastián de Lugo.

Al poco tiempo de poner el "Laus Deo» a esa colección, su autor tomó conciencia de que el tiempo iba pasando sin que se arreglase el asunto de la testamentaría de su tío Estanislao. Se dio cuenta de que si a los 75 años que se le echaban encima -corría entonces el año 1848- seguía tan intransigente, moriría sin haber cobrado una blanca. En cambio, la totalidad del legado recaería en sus primos. Entonces el canario decidió apearse de su intransigencia. Escribió a sus primos proponiéndoles, so color de «evitar gastos y disgustos consiguientes a un nuevo litigio [...] terminar este asunto confidencial y amigablemente por medio de una persona entendida y conocedora de sus derechos». Por su parte, otorgó su poder especial, amplio y sin limitación, al licenciado D. Fernando Guillerna, abogado del Colegio de la Corte, para que llegase a un acuerdo con la adversa, comprome-

17. Hay ejemplares de esta obra en el Museo canario de Las Palmas, en la Biblioteca del C.S.I.C., en la B.N. de Madrid, etc... 
tiéndose cada parte a la observancia de lo que conviniesen por escritura pública» ${ }^{18}$.

Los herederos de Don José aceptaron esa propuesta. Carlos y Emilia, por un instrumento otorgado ante el notario Dumoret de Bagnères (Mayo de 1849), y Olimpia mediante otro que dio ante el Cónsul de España en Bayona, D. Fabricio de Potestad (5-6 de Junio), dieron a su hermano Augusto un poder tan amplio como en Derecho se permite con una doble finalidad: en primer lugar, "recoger lo que les correspondiese de la sucesión de su tía Estefanía de Lugo, muerta en Canarias más de tres lustros antes y, en segundo lugar, recibir y cobrar cuanto les correspondiera de la herencia de su tío D. Estanislao..., obrar en unión con Sebastián su primo a la partición de capitales, rentas y accesorios depositados en Burdeos, provinientes de la sucesión de D. Estanislao, formar los lotes, sortearlos y distribuirlos amigablemente». Finalmente, compareciendo ante el citado cónsul de Bayona, Augusto de Lugo exhibió los poderes que se habían dado a su favor, pero ante la imposibilidad de viajar a Madrid, traspasó estos poderes, con la anuencia de sus hermanos, a D. Eleuterio Otero --u Oteo-, abogado de la Corte, a quien confirió también su propio poder.

Los letrados adoptaron una solución salomónica, dividiendo los 69.611 francos en dos partes iguales, con la condición de que previamente Sebastián devolviese los 20.000 reales que había recibido en metálico de los fondos de la herencia de Estanislao para litis expensas (n el pleito en nulidad del testamento ológrafo. Para evitar que rebrotase el pleito, los apoderados multiplicaron las garantías: las partes "se reconocen recíprocamiente por dueños libres y absolutos de las cantidades que les van adjudicadas. Aseguran otorgar esta escritura con la mayor buena fe, sin lesión ni engaños y, si lo contrario surediese, se hacen mutua donación pura y perfecta «inter vivos», obligándose a no reclamar agravios ...y que se les imponga perpetuo silencio... Y considerarán este convenio como si fuese sentencia definiiva pasada en autoridad de cosa juzgada y consentida» ${ }^{19}$. Esas prerauciones surtieron el efecto apetecido, pues ya no se oyó hablar en la familia de la herencia del tío Estanislao.

is. Transacción y convenio celebrado entre el Sr. D. Sebastián de Lugo y los hijos y herederos de D. José de Lugo, Archivo Histórico de Protocolos, Madrid, Protocolo 26.384 , notario Granja, $1 .^{\circ}$ medio-año 1850 , fols. 343-361.

19. Ibid., idem, fols. 343-346 v. 
Dieciseis años fueron pues necesarios para liquidar esta herencia peliaguda. La solución adoptada tuvo por cierto el mérito de restablecer la paz en el seno de la familia Lugo. Pero no estoy muy convencido de que la transacción final firmada por las dos partes corresponda exactamente a la voluntad de D. Estanislao. Este, en un testamento extendido de su puño y letra dejaba por cierto cuantiosos bienes sitos en su mayor parte en Aragón a su hermano D. José. Pero también, sin disputa posible, era su voluntad dejar a su hermana Estéfana y, a la rauerte de ésta, a su sobrino Sebastián una cantidad de 87.000 francos, reducida en 1850 a 69.611 francos, que le proporcionaría una renta vitalicia. La codicia insaciable de $\mathrm{D}$. José y la habilidad dialéctica de los leguleyos madrileños consiguieron quitarle la mitad de lo que buenamente era suyo, con la agravante de que durante más de tres lustros le impidieron disfrutar de esta manda.

Este retraso considerable perjudicó indudablemente al canario, al que su pensión de 4.000 rs anuales no permitía crecidos gastos. La cantidad que le tocó rondaba los 35.000 francos-oro, suma harto apreciable ya que, contando el franco francés a 4 reales de vellón, cambio que se aplicó en todos los cálculos del inventario de los bienes de Don José de Lugo, representaba aproximadamente 140.000 rs, o sea, de una vez, el equivalente de 35 años de la pensión que el gobierno-liberalmente-abonaba a Sebastián.

Ignoramos durante cuantos años pudo gozar el heredero de esa manda. En efecto, la firma del convenio familiar con sus primos constituye el último hecho que conocemos de la vida del ex-Secretario de Legación. A partir de 1850, hic et nunc, no sabemos nada de él, sino sólo que, en fecha que asimismo desconocemos, falleció en la Villa y Corte, tan soltero como lo había parido su madre.

\section{A NEXOS}

I. 28 Août 1833. Procuration en blanc par Mr. D. Joseph de LUGO, chevalier..., ancien Consul Général d'Espagne en France et en Portugal, et Commissaire Ordonnateur au service de S.M.C, demeurant à Bagnères... à l'effet de recueillir la succession de $D$. Stanislas de Lugo, son frère, Chevalier Grand Croix de L'Ordre Royal et distingué de Charles III, ancien Conseiller d'Etat et Directeur des Etudes en Espagne (sic), demeurant à Bordeaux rue Porte Dijeaux n. 67 où il est décédé le 25 Août courant.

(Arch. Départ. Tarbes, Etude Maître DAUBE, 1833, n. ${ }^{\circ} 276$ ). 
II. 2 Octobre 1833. Procuration en blanc par Mr. Don Joseph de LUGO agissant en qualité d'héritier de feu Stanislas de LUGO, son frère, aux termes de son testament olographe du 3 Janvier 1826 en faveur de... auquel il donne pouvoir de pour lui et en son nom gérer et administrer tous les biens innmeubles situés en Espagne, créances, actions et inscriptions (vales reales) dépendant de la sucession dudit feu Stanislas de LUGO, exercer et faire valoir dans ledit Royaume et en France, passer en conséquence, renouveler et résilier tous baux, moyennant les prix, charges, clauses et conditions que le constitué jugera convenables, faire tous états des lieux, inventaires, récolement, faire faire toute grosse réparation urgente, arrêter tous marchés et devis à ce sujet, faire faire par les locataires et fermiers les réparations à leur charge, transiger sur toutes les difficultés qui pourront s'élever sur l'exécution du testament dudit feu Stanislas de LUGO, révoquer toutes procurations précédentes données pour le même objet à tous autres, faire signifier ladite révocation le cas échéant, poursuivre contre le comte de Montijo le délaissement avec restitution du fruit de tous les immeubles par lui cé dés à feu Don Stanislas de LUGO aux termes d'un acte passé à Madrid le 23 Juin 1818; poursuivre également contre le comte de Cabarrús le remboursement de 28 inscriptions (vales reales) création de Janvier de 300 piastres chacune prêtées audit Cabarrús par feu Stanislas de LUGO le 13 Mai 1811 et dont le reçu est entre les mains du marquis de Perales, ainsi que les intérêts ou arrérages desdites inscriptions.

...Poursuivre toutes liquidations sur le gouvernement français et espagnol ou sur des particuliers, produire tous titres et pièces, les certifier véritables... traiter, composer, transiger, plaider, s'opposer... obtenir tous jugements, en appeler en cas de griefs...

(Mismo paradero que el documento anterior, con el n. ${ }^{\circ} 308$ )

III. 15 de Abril de 1834. Procuration en brevet par D. Sebastian de LUGO, ancien secrétaire d'Ambassade, domicilié à Madrid et demeurant momentanément à Bagnères.

Il constitue pour son mandataire général et spécial Maître Fleuri GODDE, demeurant et domicilié à Bordeaux, auquel il donne pouvoir de, pour lui et son nom, s'opposer à ce que le testament olographe de feu D. Stanislas de LUGO soit déposé dans l'étude d'un notaire de la ville de Bordeaux, comme se propose de le demander D. Joseph de LUGO, l'un des héritiers testamentaires.

A cet effet décliner devant qui de droit la compétence des tribunaux français pour la décision des questions et difficultés que l'exécution du testament peut ou pourra faire naître ainsi que de celles dérivant de son interprétation qui toutes, sont de la compétence des tribunaux espagnols, attendu que le testateur est décédé espagnol et que tous ses héritiers ou légataires nommés sont espagnols, ainsi que trois exécuteurs testamentaires.

Comparaître devant tous juges et tribunaux s'il est nécessaire pour y proposer le déclinatoire et faire ordonner que les exécuteurs testamentaires seront tenus de déposer ledit testament à l'étude d'un notaire à Madrid d'après les formes des lois espagnoles.

Faire notifier par les officiers ministériels audit Joseph de LUGO le déclinatoire dont s'agit avec protestation que le constituant fera valoir lesdits droits résultant pour lui dudit testament devant les tribunaux espagnols en 
y appelant ledit D. Joseph de LUGO et tous autres légataires si cela devient nécessaire.

De substituer à toute autre personne tout ou partie des présents pouvoirs (Ibid., 1834, n. ${ }^{\circ} 120$ ).

IV. 12 Juin 1834. Procuration de D. Sebastien de LUGO sur le même sujet. Il se trouve encore momentanément à Bagnères.

Donne pouvoir à Mr. Fleuri GODDE de s'opposer a ce que le testament olographe de D. Stanislas de LUGO soit déposé dans l'étude d'un notaire de Bordeaux etc., etc. (texte identique avec quelques compléments). Donne pouvoir pour:-faire aux fins ci-dessus tout ce qui pourra être exigé par les circonstances, comme de constituer avoué et défenseurs devant les tribunaux de Bordeaux et autres tribunaux français, les révoquer... faire toutes diligences exigées auprés de l'Ambassade d'Espagne et autres autorités espagnoles en France pour faire exécuter les traités existants entre les deux nations et faire jouir le constituant des avantages et bénéfices desdits traités et notamment du droit de décliner la compétence des Tribunaux français, pour faire exécuter les traités existants entre les deux nations et faire jouir le constituant des avantages et bénéfices desdits traités et notamment du droit de décliner la compétence des Tribunaux français, de substituer à toute autre personne tout ou partie des présents pouvoirs... (Ibid., DAUBE, n. $\left.{ }^{0} 194\right)$.

V. 12 Août 1834. Certificat de vie de Mr. Don Sebastian de LUGO. Il dit qu'il est en congé et momentanément domicilié à Bagnères. (Ibid., DAUBE, 1834, n. $\left.{ }^{\circ} 263\right)$. 